CAPSULE COMMENTARIES

\title{
Capsule Commentary on Glod et al., Clerkship Roles and Responsibilities in a Rapidly Changing Landscape: a National Survey of Internal Medicine Clerkship Directors
}

\author{
Christopher A. Feddock, M.D., M.D., FAAP, FACP \\ University of Kentucky College of Medicine, Lexington, USA. \\ J Gen Intern Med 35(5): 1623 \\ DOI: $10.1007 / \mathrm{s} 11606-020-05716-2$ \\ (c) Society of General Internal Medicine 2020
}

G lod et al. ${ }^{1}$ provide insight into the current role of internal medicine (IM) clerkship directors (CDs). The $83 \%$ response rate from the 129 LCME-accredited US medical schools with CDIM membership provides confidence that the results reflect today's state. Because of differences in design and content, this survey is not directly comparable to the last large survey of CDs conducted in $2007^{2}$; however, certain trends emerge. Although the 2003 Alliance for Clinical Education (ACE) statement recommended 50\% salary support, ${ }^{3}$ the 2007 survey from multiple disciplines found an average of $22 \%$ salary support, ${ }^{2}$ and the current IM CDs report between 21 and $50 \%$ with two-thirds supported $40 \%$ or less. Similarly, $40 \%$ of 2007 CDs had a discretionary budget ${ }^{2}$ compared with $35 \%$ of IM CDs in the current study. The current role is also complex - $40 \%$ of IM CDs report to the dean of curriculum, $70 \%$ direct other clinical experiences, including electives and subinternships, and $61 \%$ supervise other faculty members.

Although the 2003 ACE statement remains the primary guide for CDs, support appears stagnant at levels well below recommendations. Further, contemporary clinical education has little resemblance to 2003. At that time, 125 medical schools existed, the third year of medical school was synonymous with the clerkship year, nearly all students passed USMLE step 1 prior to their clerkships, and USMLE step $2 \mathrm{CS}$ did not exist. Today, 154 schools are LCME-accredited, ${ }^{4}$ and almost one-third operate regional campuses. ${ }^{5}$ This expansion has further strained clinical education as $85 \%$ of schools are concerned about the availability of clinical sites. ${ }^{4}$ Although obstetrics-gynecology and pediatrics are the most challenging, $26 \%$ of schools had difficulty finding IM clinical training sites in 2018. ${ }^{4}$ These pressures have necessitated further collaboration with the dean's office as evidenced by the number of IM CDs who report to the curriculum dean. Although this study provides additional insight, we still have an incomplete understanding of how medical schools structure clerkship responsibilities. Further research on $\mathrm{CD}$ activities across all specialties is necessary to guide medical school decisions on clinical education support.

Corresponding Author: Christopher A. Feddock, M.D., M.D., FAAP, FACP; University of Kentucky College of Medicine, Lexington, USA (e-mail: Chris.feddock@uky.edu).

\section{Compliance with Ethical Standards:}

Conflict of Interest: The author declares that he does not have a conflict of interest.

\section{REFERENCES}

1. Glod S, Alexandraki I, Jasti H, Lai CJ, Ratliff TA, Walsh K, Kisielewski M, LaRochelle J. Clerkship Roles and Responsibilities in a Rapidly Changing Landscape: A National Survey of Internal Medicine Clerkship Directors. J Gen Intern Med. DOI: https://doi.org/10.1007/s11606-01905610-6.

2. Ephgrave K, Margo KL, White C, Hammoud M, Brodkey A, Painter T, Juel VC, Shaw D, Ferguson $\mathbf{K}$. Core clerkship directors: their current resources and the rewards of the role. Acad Med. 2010;85(4):710-5.

3. Pangaro L, Bachicha J, Brodkey A, Chumley-Jones H, Fincher RM, Gelb D, Morgenstern B, Sachdeva AK; Alliance for Clinical Education. Expectations of and for clerkship directors: a collaborative statement from the Alliance for Clinical Education. Teach Learn Med. 2003 Summer; 15(3):217-22.

4. Association of American Medical Colleges. Results of the 2018 Medical School Enrollment Survey. Washington, D.C.: 2019.

5. Association of American Medical Colleges. LCME Annual Medical School Questionnaire Part II, 2011-2012 through 2017-2018. https://www. aamc.org/data-reports/curriculum-reports/report/curriculum-reports. Accessed 10/30/2019.

Publisher's Note Springer Nature remains neutral with regard to jurisdictional claims in published maps and institutional affiliations. 